$\begin{array}{ll} & \text { Etnográfica } \\ \text { etnográfica } & \text { Revista do Centro em Rede de Investigação em }\end{array}$

Antropologia

vol. 25 (1) | 2021

Vol. $25(1)$

\title{
Economia, trabalho e turismo: encontros e desencontros em visitas turísticas a fábricas em laboração
}

Economy, work and tourism: encounters and failed encounters in touristic visits to working factories

\section{Mariana Silva}

\section{(2) OpenEdition}

\section{Journals}

\section{Edição electrónica}

URL: https://journals.openedition.org/etnografica/9858

DOI: 10.4000/etnografica.9858

ISSN: 2182-2891

\section{Editora}

Centro em Rede de Investigação em Antropologia

\section{Edição impressa}

Paginação: 131-148

ISSN: 0873-6561

\section{Refêrencia eletrónica}

Mariana Silva, «Economia, trabalho e turismo: encontros e desencontros em visitas turísticas a

fábricas em laboração», Etnográfica [Online], vol. 25 (1) | 2021, posto online no dia 05 março 2021, consultado o 29 janeiro 2022. URL: http://journals.openedition.org/etnografica/9858 ; DOI: https:// doi.org/10.4000/etnografica.9858

\section{(c) (7) (8)}

Etnográfica is licensed under a Creative Commons Attribution-NonCommercial 4.0 International License. 


\section{Economia, trabalho e turismo: encontros e desencontros em visitas turísticas a fábricas em laboração}

\section{Mariana Silva}

São João da Madeira é uma pequena cidade portuguesa com um tecido económico consolidado em torno da indústria e que, desde cedo, construiu a partir do signo do trabalho a sua retórica de diferenciação. Mais recentemente, alguns agentes locais começaram a olhar para esta dimensão industrial também do ponto de vista do seu potencial turístico, o que resultou na criação de um projeto de turismo industrial que conjuga visitas a museus industriais, fábricas em laboração e instituições complementares da atividade industrial. A partir de uma etnografia dos circuitos de turismo industrial de São João da Madeira, com enfoque nas visitas a fábricas em laboração e adotando perspetivas teóricas que colocam os sujeitos turísticos no centro da reflexão, o artigo analisa as subjetividades reflexivas mobilizadas no encontro turístico entre visitantes e trabalhadores fabris. Estas visitas turísticas revelam a capacidade reflexiva destes sujeitos sociais através do modo como convocam, negoceiam e hierarquizam teias de significados, tensões e ideias de futuro numa sociedade marcada pelo impacto de uma reestruturação produtiva à escala global e pela ansiedade provocada pelas (re)configurações atuais do trabalho.

PALAVRAS-CHAVE: turismo industrial, encontro turístico, indústria, economia, trabalho.

Economy, work and tourism: encounters and failed encounters in touristic visits to working factories - São João da Madeira is a small town with an economic fabric anchored in industry, which has built, from very early on, its differentiation rhetoric under the banner of work. More recently, some local agents also started to look at the touristic potential of this industrial dimension. In 2012 an industrial tourism project was launched, combining visits to industrial museums, working factories and other industrial institutions. Drawing on ethnographic field notes on the industrial tourism circuits of São João da Madeira, with a focus on the visits to working factories and adopting theoretical perspectives that place tourist subjects in the centre of the reflection, the article analyses the reflexive subjectivities mobilised on the tourist encounter between factory workers and tourists. Such touristic visits reveal the reflexive capability of these social agents, as they allow webs of meaning, tensions and ideas of the future to be mobilised, negotiated and ranked in a society marked by the impact of a global production restructuring and the anxiety caused by the current (re)configurations of work.

KEYWORDS: industrial tourism, tourist encounter, industry, economy, work.

SILVA, Mariana (marianasilva413@gmail.com) - NOVA-FCSH; ISCTE-IUL; CRIA-FCSH, Portugal. 
FÁBRICA. ÁREA DE PRODUÇÃO OU "CHÃO DE FÁBRICA". ${ }^{1}$ MAIS UM DIA de trabalho. Todos os trabalhadores estão no seu lugar, entre máquinas, mesas de trabalho, ferramentas e mercadorias em construção. Lá ao fundo avistam-se as batas brancas. É uma visita que está a chegar. Qualquer conversa paralela fica interrompida por instantes. Até o rádio que alegra o ambiente sonoro é colocado em silêncio, para dar privilégio às sonoridades das máquinas. Alguns trabalhadores têm a preocupação de verificar se o seu posto de trabalho está organizado para que os visitantes consigam perceber o que fazem todos os dias. Por vezes, alguns até desaceleram o ritmo dos seus gestos para o tempo do trabalho coincidir com o tempo do lazer. Outras vezes, fazem algo mais do que o previsto, até em jeito de simulacro, só para os visitantes "conseguirem ver". Chega o guia com o grupo e explica. Pode, ou não, fazer alguma pergunta e avança. Os visitantes também têm a liberdade de interpelar os trabalhadores e não raras vezes o fazem. Frente a frente com todo o grupo, ou uns passos atrás, fugindo aos tempos e percursos estabelecidos. O guia fica com a tarefa de captar a atenção de todos os visitantes, quase em competição com a oportunidade de estar perto e de trocar impressões com aqueles que são os detentores dos conhecimentos e vivências que eles vieram ali conhecer. Trocas de impressões que muitas vezes obrigam à proximidade dos rostos, como que em registo de conversa íntima, porque o ruído de um espaço fabril assim o obriga, para o bem da comunicação, mas também porque as palavras que se trocam, muitas vezes, parecem não ter direito a ser proferidas em voz alta.

No entendimento do turismo como um conjunto complexo de discursos e práticas, trabalhos recentes neste campo de estudos têm vindo a distanciar-se da tendência de construção de grandes modelos teóricos explicativos, das críticas ao turismo como um modo de imperialismo cultural e dos estudos dos seus impactos, para se concentrarem na análise do particular, da pluralidade e da complexidade das práticas turísticas (Sampaio 2013). Com uma atenção à diversidade e agencialidade dos atores turísticos, o encontro turístico apontado como o coração do turismo, enquanto embodied practice (Crouch, Aronsson e Wahlstrom 2001), surge como protagonista não só da experiência turística em si, mas igualmente deste tipo de estudos (Gibson 2010).

A partir de uma análise aos circuitos de turismo industrial de uma pequena cidade portuguesa (São João da Madeira), com enfoque nas visitas a fábricas em laboração, este artigo tomará em consideração, precisamente, as subjetividades reflexivas mobilizadas no encontro turístico entre visitantes e trabalhadores fabris. Adotando um entendimento das práticas turísticas como formas de relação com o outro, o objetivo do artigo é analisar os modos como a ativação turística de espaços contemporâneos de produção industrial é capaz de convocar, negociar e hierarquizar múltiplas ideias sobre economia e trabalho, 
tendencialmente mais críticas do que as visões higienizadas e estetizadas dos discursos e práticas oficiais.

$\mathrm{O}$ artigo apresenta alguns resultados preliminares de parte de uma pesquisa etnográfica, desenvolvida no âmbito de uma investigação de doutoramento sobre processos de patrimonialização e turistificação da indústria em São João da Madeira, desde a última década do século XX até aos dias de hoje, que pretende dar conta de múltiplas vozes, incluindo decisores políticos e técnicos do património e turismo, empresários e trabalhadores da indústria, população local e visitantes. ${ }^{2}$ Foi na busca pelas teias de significados (Geertz 1977 [1973]) projetadas pelos visitantes de fábricas em laboração em torno das ideias de indústria, economia e trabalho, que a relevância do encontro turístico se impôs no decorrer do trabalho de campo. A justificação para a escolha deste dispositivo de análise encontra-se, num primeiro momento, visível na vinheta etnográfica que abre este artigo. Recorrendo aos métodos de observação participante e a conversas informais, entrei nas fábricas com grupos de visitantes, estive ao lado dos trabalhadores antes, durante e depois das visitas, e cheguei a ser guia de várias visitas. ${ }^{3}$ Aqui, visita após visita, os arranjos diários das interações entre visitantes e trabalhadores, no cruzamento entre o contacto simultaneamente público e íntimo, foram reveladores do modo como as representações que procurava eram filtradas pelo prisma do encontro turístico. Foi assim que a proposta de Maria Cardeira da Silva (2004) sobre os contributos da antropologia para os estudos do turismo se tornou mais clara, confirmando a capacidade de a antropologia, através dos seus instrumentos clássicos, tomar em atenção os múltiplos atores envolvidos no fenómeno turístico, as suas relações, práticas e representações, partindo da premissa de que o turismo assenta numa relação onde o princípio de alteridade está sempre presente.

\section{INDÚSTRIA, PATRIMÓNIO E TURISMO}

O alargamento do conceito de património é uma evidência. A ideia de património naturalizou-se. Já em meados da década de 1980, Lowenthal referia que o "património está em todo lado" 4 (201 l [1985]: xiii). Com efeito,

2 A referida investigação está a ser levada a cabo no âmbito do programa de doutoramento FCT em Antropologia - "Políticas e Imagens da Cultura e Museologia" (NOVA FCSH/ISCTE-IUL), sob orientação de João Leal, com financiamento da FCT - Fundação para a Ciência e a Tecnologia (PD/BD/1 13 943/2015). Agradeço os comentários e sugestões dos pareceristas e editores da revista Etnográfica a uma versão preliminar deste artigo.

3 O período de trabalho de campo dedicado aos circuitos de turismo industrial decorreu entre janeiro e junho de 2017. As referências anteriores a este intervalo temporal correspondem a um período de trabalho de campo de natureza exploratória, desenvolvido desde abril de 2015 enquanto guia em algumas destas visitas.

4 As citações e conceitos em língua estrangeira serão traduzidos pela autora para português sempre que tal não prejudique o seu entendimento. 
aquilo que hoje é entendido como património abarca quase tudo o que nos rodeia ou tudo aquilo que seja capaz de nos fazer olhar para o passado e, na expressão de Nora (1984-1992), que possa ser entendido enquanto "lugar de memória”. Por outro lado, o que nos é próximo tem hoje também - e de forma cada vez mais rápida - a capacidade de se tornar memória. Isto conduz ao que Bendix (2009) descreveu como uma aproximação no eixo social e temporal do campo do património e, consequentemente, a uma maior abertura e expansão do mesmo. Apesar das suas especificidades, é também dentro deste contexto que deverá ser entendida a emergência da categoria de património industrial.

Com a industrialização e o desenvolvimento da sociedade capitalista, a forma como nos relacionamos com os objetos que nos rodeiam alterou-se profundamente. Há muito que a maior parte de nós já não produz o que come ou o que veste. Mas o fenómeno da cadeia global de produção e de mercado, com destaque para a deslocalização de uma parcela substancial da produção industrial para novas geografias, tem reforçado o afastamento de grande parte das primeiras populações industrializadas dos modos de fazer as coisas de que necessitam para viver. Economias impulsionadas pela atividade industrial deram lugar a economias predominantemente baseadas nos serviços, com um forte peso das tecnologias. As fábricas deixaram de ser as grandes empregadoras da força de trabalho. Neste contexto de afastamento das populações dos meios de produção acentuou-se o fascínio pela descoberta dos processos de fabrico de produtos industriais, consumidos diariamente. Ou seja, já não são apenas os primórdios da sociedade industrial que são um "país estrangeiro" (Lowenthal 2011 [1985]), mas é também a atual atividade industrial que se encontra cada vez mais distante do nosso quotidiano.

Se os processos contemporâneos de alargamento do conceito de património decorrem de um conjunto de discursos e práticas em torno da preservação de um passado cada vez mais próximo, como garantia de estabilidade e continuidade, estes também se encontram associados à formulação e implementação de políticas de visibilidade e de desenvolvimento a múltiplas escalas, que veem no património um recurso suscetível de rentabilização social e económica por via do turismo. Muitas vezes, é também pela ausência de outros atributos turísticos mais tradicionais - sol e mar, natureza e gastronomia - que, em territórios historicamente vinculados à indústria, lugares de produção industrial do passado, mas também do presente, se tornam mercantilizáveis, transformando-se em produto para consumo turístico, onde o trabalho de uns se torna parte do ócio de outros. Ou seja, com o distanciamento temporal, espacial e social das populações perante o trabalho industrial, estes espaços convertem-se, por via do turismo, em novos lugares de excursão com significados distintos. Os mais jovens, que nunca entraram numa fábrica, vão por norma à procura do exótico, entendido como o que é diferente e desconhecido. Já para antigos 
trabalhadores fabris, a nostalgia é essencial, numa experiência de "retorno às suas raízes" (cit. Gouthro 2008: 82).

O exotismo da indústria foi posto em evidência desde as primeiras grandes exposições universais do século XIX, ${ }^{5}$ por vezes consideradas como os primórdios do turismo industrial. Concebidas como exposições de ciência e indústria, procedentes da Revolução Industrial, estas exposições foram espetáculos que muito provavelmente se tornaram em "laboratórios de exotismo, turismo e consumismo" (cit. Xie 2015: 38). Com um papel fundamental para a consolidação daquilo que se instituiu como sociedade industrial, as grandes exposições universais foram representações fervorosas de um novo modelo económico baseado em ideias de progresso e bem comum (Gouzévitch, Lourenço e Matos 2010), ao mesmo tempo que contribuíram para a definição de um lazer de multidões até então desconhecido (Corbin 2001 [1995]). Porém, com a expansão da produção industrial e a crescente curiosidade em torno das inovações da mecanização, as tours industriais começaram igualmente a ganhar popularidade ainda no século XIX, por exemplo nos Estados Unidos da América, com fábricas a realizarem visitas às suas instalações dirigidas ao público em geral, já com propósitos de marketing subjacentes (Marsh 2008).

As práticas turísticas e de lazer têm sido predominantemente vistas como constitutivas dos sujeitos modernos, na sua relação dialética com o domínio do trabalho, que atingiu um nível de importância social sem precedentes com a industrialização. Para além da apologia de uma necessidade universal de recreação dos seres humanos (Graburn 1989 [1977]), foi na fuga à rotina do quotidiano do trabalho que a possibilidade de satisfazer essa necessidade surgiu para uma nova e grande massa de trabalhadores. Como Corbin demonstrou (2001 [1995]), no início do século XIX, o tempo do trabalho era ainda descontínuo - i.e., entre este e o tempo sem trabalho não existia uma distinção marcada, encontrando-se as duas categorias em interação. É a partir de meados do século XIX, com a reformulação dos ritmos de trabalho da Revolução Industrial, que se começou a formar uma nova distribuição dos tempos sociais para as classes populares e se assistiu a uma progressiva distinção do tempo do trabalho e do tempo do lazer. Como conclui o autor, foi com a regulação social do tempo moderno que as práticas turísticas e de lazer começaram a democratizar-se e deixaram de ser privilégio das classes mais altas.

Contudo, como defende MacCannell (1999 [1976]), é a partir dos movimentos sociais, políticos e económicos da década de 1960 que o trabalho vê alavancado o seu caráter de objeto de curiosidade turística, passando a ser exibido em cada vez mais museus de ciência e/ou indústria e em fábricas que

5 A primeira exposição universal data de 1851 e realizou-se em Londres, com o título de Grande Exposição dos Trabalhos da Indústria de Todas as Nações (Gouzévitch, Lourenço e Matos 2010). 
abriam as suas portas aos turistas. ${ }^{6}$ A esta prática cultural o autor chamou work display (idem: 36 ).

Com a expansão da categoria de património industrial e do número de museus relacionados, assistiu-se ao aumento progressivo dos seus usos turísticos. A partir dos anos de 1980, as visitas a fábricas em laboração começaram também a ser estruturadas enquanto oferta turística organizada, muitas vezes a partir de parcerias entre as empresas e organizações regionais de promoção dos territórios (cf. Cordeiro 2012).

\section{DA PRODUÇÃO INDUSTRIAL À EXIBIÇÃO DO "REAL": TURISMO INDUSTRIAL NUMA PEQUENA CIDADE PORTUGUESA}

São João da Madeira é uma cidade portuguesa de cerca de 20 mil habitantes com um tecido económico consolidado em torno da indústria que, desde o início do século XX, tem vindo a construir, a partir do signo do trabalho, a sua retórica de diferenciação. ${ }^{7}$ Mais recentemente, alguns agentes locais começaram a olhar para esta dimensão industrial também do ponto de vista do seu cunho patrimonial e turístico. Foi no património industrial local e na dimensão contemporânea ligada à indústria que o poder político identificou uma oportunidade de rentabilização turística dos recursos locais, com o fim de atrair fluxos significativos de visitantes. Em janeiro de 2012, o município lançou um projeto de turismo industrial, constituído por um conjunto de circuitos turísticos, com o objetivo de conjugar a preservação do espólio de arqueologia industrial do concelho com a divulgação das indústrias tradicionais, bem

6 Começou até a surgir uma nova retórica turística em algumas grandes atrações, como por exemplo as pirâmides do Egipto, que passaram a aparecer como representações monumentais daquilo que Karl Marx costumava designar como o "trabalho humano abstrato e indiferenciado", chegando mesmo a substituir, por vezes, os significados sociais e religiosos originais (MacCannell 1999 [1976]: 6).

7 Trata-se do concelho com o território mais pequeno do país, com cerca de $8 \mathrm{~km}^{2}$ e apenas uma única freguesia. Apesar da sua reduzida dimensão territorial, desde cedo se distinguiu como uma das localidades mais dinâmicas do tecido industrial português. Pela sua localização, integra uma região que se consolidou como espaço predominantemente industrial, sob a égide do centro comercial e industrial que é a cidade do Porto. Esta vocação industrial vem já desde o fim do século XIX e foi o mote, em 1926, para a desanexação da freguesia de São João da Madeira do concelho de Oliveira de Azeméis e, consequente, emancipação concelhia (M. Silva 2015). Ao pioneirismo da indústria de chapelaria juntaram-se, principalmente a partir do início do segundo quartel do século XX, as indústrias do calçado e da metalurgia - com a fundação da fábrica Oliva -, que paulatinamente foram retirando à chapelaria a posição hegemónica no que toca à absorção de mão-de-obra e ao peso económico no tecido industrial local (Estanque 1999). Atualmente, a atividade industrial continua a ser o principal motor da economia local, com 45\% da população ativa a trabalhar no setor secundário (INE 2011). A diversidade industrial tornou-se uma evidência, não só com a emergência das indústrias tecnológicas e criativas, mas também no quadro das chamadas indústrias tradicionais. À indústria de chapelaria e de calçado juntou-se, desde a segunda metade do século xx, a indústria dos colchões e a de componentes para automóveis, entre outras. 
como das novas indústrias tecnológicas e criativas, através de visitas a museus industriais, fábricas em laboração e instituições complementares da atividade industrial. $^{8}$

A atenção ao património industrial e a integração de lugares industriais nos circuitos do turismo têm vindo a configurar-se como um recurso cada vez mais mobilizado em cidades fortemente afetadas com o declínio do seu tecido industrial, muitas vezes numa tentativa de revitalização económica face à perda da indústria (Hewison 1987). Por vezes, processos de salvaguarda e revitalização com fins turísticos de fábricas em declínio ou encerradas surgem quando medidas alternativas se mostraram inviáveis (Llurdés I Coit 2001). A par da aposta no empreendedorismo e na inovação tecnológica e criativa, a promoção do turismo industrial passou a ser vista como uma ferramenta política adicional para a regeneração destas economias locais (Hospers 2002).

No entanto, em São João da Madeira, não se pode afirmar que o património e o turismo industrial tenham entrado em ação como resposta ao fim da indústria. Mesmo com os efeitos de vários ciclos de crise, que conduziram ao encerramento de algumas fábricas importantes, ${ }^{9}$ essa perda total não existiu. Apesar de a criação dos circuitos turísticos industriais ter como objetivo obter retorno económico direto, o que encontrei aqui em causa foi, sobretudo, a aposta na construção de uma imagem capaz de representar a cidade para além do seu território, tal como já se encontra expresso no documento oficial que define como estratégia local a criação de um projeto de turismo industrial (Plano de Desenvolvimento Local, 2008). Ao replicar à escala local o entendimento do turismo como "agência de marketing", já veiculado em escalas nacionais (Lofgren 1989), mais do que estarmos perante uma política de reestruturação económica por via do turismo, no quadro de uma viragem para o universo dos serviços, assiste-se à adoção do turismo industrial enquanto ferramenta de relações públicas para promover a imagem de um território e do seu tecido industrial. Com efeito, para além de outros usos complementares e concomitantes, este projeto assume igualmente como missão a valorização do trabalho industrial e dos seus protagonistas, no sentido de tentar combater determinadas ideias públicas menos positivas sobre o universo fabril.

8 O projeto oferece, atualmente, a possibilidade de visita a empresas e instituições associadas ao setor da chapelaria (duas empresas), calçado (duas empresas e duas instituições), colchões (duas empresas), acessórios têxteis (uma empresa), artes gráficas (uma empresa) e lápis (uma empresa), bem como ao Museu da Chapelaria, ao Museu do Calçado, ao centro de indústrias tecnológicas, a Sanjotec, ao centro de indústrias criativas, a Oliva Creative Factory, e a parte das antigas instalações da fábrica Oliva - Torre da Oliva (<http://turismoindustrial.cm-sjm.pt > última consulta em outubro de 2019).

9 Exemplo disso foi o encerramento da Empresa Industrial de Chapelaria (1914-1996) e da metalúrgica Oliva (1925-2010), as duas maiores fábricas do concelho durante o século XX (M. Silva 2015). 
Numa hibridização de modelos de influência de outros países europeus, ${ }^{10}$ estes circuitos afirmam o seu pioneirismo ao nível nacional pelo modelo de gestão centralizado no município, ${ }^{11}$ com visitas ao património industrial e a fábricas em laboração, numa conjugação entre a cultura técnica e a descoberta económica:

"Já pensou visitar uma fábrica em plena laboração? Em S. João da Madeira, abrimos as portas das nossas unidades e mostramos-lhe aquilo que de melhor se faz no concelho, quer em ambientes altamente tecnológicos, quer em contextos que mantêm tradições centenárias. Conviva com o futuro, reviva atividades de outros tempos e conheça a história da região. Aqui pode ver como se faz um sapato, com que materiais se confeciona um chapéu, como se tecem etiquetas, fitas e elásticos, e como se coloca uma mina dentro do lápis. Pode ainda sentir o cheiro do cedro na Viarco [fábrica de lápis] e o do couro na Evereste e na Helsar [fábricas de calçado]. A riqueza do património industrial de $\mathrm{S}$. João da Madeira serve de mote a um novo conceito de turismo de experiência, apenas possível ser vivido nos 'Circuitos pelo Património Industrial', em S. João da Madeira. Aceite o nosso convite. Esperamos por si..." [folheto de promoção Turismo Industrial: S. João da Madeira, 2012].

A perceção do distanciamento das vivências industriais é capitalizada na retórica turística: "mas a fábrica ainda está aberta?"; “veem-se pessoas a trabalhar?"; "as máquinas estão a trabalhar?" - são questões frequentes em qualquer ação de promoção e comunicação do projeto. Uma linha de montagem industrial tornou-se um produto quase tão exótico e apetecível como uma qualquer manifestação de um último recôndito de cultura popular:

"Realmente nós sabemos que no Norte há muita indústria. Mas não vemos. Toda esta gente realmente não pode trabalhar em lojas e cafés. Aqui

10 O enfoque concedido às visitas a fábricas em laboração teve a sua principal inspiração no modelo francês de turismo industrial. Na década de 1980, em França, perante uma crise do sistema industrial e a necessidade de desenvolvimento de novos produtos turísticos, no sentido de manter a sua posição no mercado mundial do turismo, surge o impulso para a reunião de vários parceiros em torno do turismo industrial. Deste modo, por iniciativa da Secretaria de Estado do Turismo, em 1985, foi criada a associação Une France à Découvrir, que reuniu Estado central, empresas, sindicatos, etc. Com o fim de promover a imagem económica do país, a associação tinha como missão proporcionar a descoberta e o desenvolvimento do valor do património industrial, das empresas em atividade, das grandes realizações técnicas e dos museus científicos e técnicos (Damien e Sobry 2001).

11 O modelo de gestão municipal, pioneiro em Portugal, pressupõe que o município de São João da Madeira seja responsável pela gestão, a marcação das visitas e a disponibilização de guias próprios e equipamentos necessários para a realização das mesmas. 
vemos. Temos contacto com os processos e com os trabalhadores. Muito interessante. Eu sou da Figueira da Foz e lá é essencialmente comércio e serviços. Não temos contacto com a indústria" [visitante português, estudante universitário, maio de 2017].

Mas não é só o contacto nostálgico com um mundo que parecia em vias de desaparecimento que tem capacidade para atrair visitantes a estas fábricas em laboração. Ou o interesse por conhecer processos de fabrico do passado a servir os propósitos de hoje, lado a lado com as mais recentes inovações tecnológicas que remetem para o caráter futurista que a indústria sempre teve. É também o contacto com aquilo que os visitantes designam como o "real", que aqui assume duas configurações. Uma primeira define-se em oposição às ideias de encenação e simulacro, cada vez mais associadas às práticas do turismo:

"Não é um produto criado para turista ver. Não é encenado como vemos cada vez mais. Acho maravilhoso passarmos no meio dos trabalhadores e estes continuarem na sua vida" [visitante portuguesa, professora, maio de 2017].

Distante dos locais onde se realizam fórmulas encenadas para turistas, que permitem que a vida quotidiana ocorra longe do seu olhar, numa hibridização entre o clássico par backstage e front stage (MacCannell 1999 [1976]), este tipo de visita turística enquadra-se na tendência de trazer para o front stage aquilo que parecia reservado ao backstage, enquadrado por uma aura de acesso restrito. Certo é que quando, no fim do século XIX, algumas fábricas norte-americanas começaram a abrir as suas portas a turistas, estas visitas eram já vistas como um acesso aos "bastidores para espreitar a produção mecanizada" (Marsh 2008: 378). Porém, numa tentativa de ir além da questão da autenticidade - que motivou MacCannell (1999 [1976]) -, o importante, como Sampaio (2013) sugere, é refletir sobre a relação entre o visível e o invisível que este binómio nos levanta, e como, neste caso, os processos sociais e culturais associados ao turismo são capazes de dar visibilidade ao que habitualmente estava remetido à invisibilidade, não deixando de criar novas invisibilidades.

Por fim, em contraste com a perceção da fragilidade do setor da banca e do próprio setor do turismo, a indústria surge para muitos destes visitantes também como a representante da economia real. O contacto direto com a realidade e o presente de uma indústria tem a capacidade de mobilizar, negociar e hierarquizar diferentes teias de significado sobre as ideias de economia e trabalho, numa sociedade marcada pelo impacto de uma reestruturação produtiva à escala global e por novas modalidades de trabalho. 
ENTRE O ATOR E O ESPETADOR:

\section{UMA ANATOMIA DO ENCONTRO TURÍSTICO}

Naquela que é identificada como a primeira zona industrial de São João da Madeira, onde nos tempos áureos de duas das maiores fábricas que a cidade já conheceu circulavam diariamente milhares de trabalhadores, ${ }^{12}$ chegam hoje, em ritmo também quase diário, autocarros cheios de visitantes. Estacionam no parque construído sobre o vazio deixado pela demolição das antigas instalações fabris da primeira marca de sapatilhas portuguesas. ${ }^{13}$ Os visitantes saem dos autocarros e são recebidos no Welcome Center do Turismo Industrial, localizado num dos ícones de arquitetura industrial da cidade, a torre da fábrica Oliva. Vestem batas brancas que os identificarão como pessoas externas às fábricas, ficando bem clara a distinção entre os de fora e os de dentro, e voltam para os autocarros, que partem em direção aos diversos locais visitáveis. Pouco circulam pela cidade sem ser de autocarro. Não consomem, a não ser nos poucos restaurantes que existem nas redondezas do Welcome Center ou no centro comercial local. São muito poucos aqueles que pernoitam. $\mathrm{Na}$ cidade, poucos os veem. Muitos dos locais não lhes reconhecem benefícios efetivos. As grandes fábricas onde se trabalhava, agora encerradas, ${ }^{14}$ foram reconvertidas em algo que não lhes dá emprego. As fábricas davam-lhes trabalho; o turismo dá-lhes muito pouco. Mesmo nas fábricas em laboração que integram os circuitos, não é o turismo que dita a contratação ou não de mais trabalhadores. Efetivamente, há análises que apontam como uma das limitações das atividades de turismo industrial o impacto relativamente baixo ao nível da criação de emprego, tanto mais em comparação com o número de lugares de trabalho perdidos aquando do encerramento de antigas fábricas (Hospers 2002).

12 Era nesta zona que se encontravam as instalações da Empresa Industrial de Chapelaria (1914-1996) e da metalúrgica Oliva (1925-2010). Após o encerramento destas fábricas, parte dos seus complexos fabris foram adquiridos pelo município e reconvertidos em equipamentos culturais, turísticos e da área das indústrias culturais e criativas. O edifício da Empresa Industrial de Chapelaria é hoje o Museu da Chapelaria. Num dos edifícios do complexo Oliva, a Torre da Oliva, encontra-se o Welcome Center do Turismo Industrial e o Museu do Calçado. Noutro edifício do mesmo complexo estão as instalações da Oliva Creative Factory, composta por um centro de negócios de indústrias culturais e criativas, um museu dedicado à arte contemporânea e arte bruta, escolas e centros de formação na área das artes plásticas e do espetáculo e sedes de associações locais.

13 A produção de sapatilhas Sanjo teve início em 1933, no âmbito de uma medida de diversificação de produção da Empresa Industrial de Chapelaria. Apenas em 1944 é construído o edifício autónomo para produção das sapatilhas com sola vulcanizada e a parte cima em lona. A empresa encerrou em 1996.

14 Para além da instalação do Welcome Center do Turismo Industrial no edifício da Torre da Oliva, nesse mesmo edifício encontra-se o Núcleo Histórico da Oliva e o Museu do Calçado. Em outro edifício da metalúrgica Oliva também se encontra o Centro de Arte Oliva, museu que acolhe duas coleções privadas de arte contemporânea e arte bruta. Em parte das instalações da Empresa Industrial de Chapelaria fica o Museu da Chapelaria. 
Em contraponto a esta quase invisibilidade do turismo no espaço público da cidade, as visitas turísticas são já uma marca do dia-a-dia de algumas das fábricas visitáveis. "Então hoje há mais visitas?", perguntam frequentemente os trabalhadores aos guias. "Enquanto há visitas nós distraímo-nos um pouco e conversamos com eles", disse-me uma trabalhadora, para quem estas visitas são um momento de fuga feliz ao quotidiano de trabalho.

A curiosidade pela localidade de origem dos visitantes é, por exemplo, questão regular durante as visitas. "De onde são?", perguntam os trabalhadores. A distância tem a capacidade de capitalizar o status do grupo. Pedidos particulares derivados da origem geográfica dos visitantes também podem ocorrer. Foi o caso da visita de um grupo de crianças de Fátima (Leiria), nas vésperas da visita papal, em maio de 2017, onde tentar perceber se os mais pequenos sabiam de quartos disponíveis para arrendar nos dias da visita foi a grande inquietação dos trabalhadores. Porém, quando ao longe percebem que a visita está a ser conduzida em língua que não o português, o burburinho aumenta de tom. O encontro com o exótico toma dupla direção. Câmaras fotográficas podem surgir não só nas mãos dos visitantes, mas também do lado de quem está dentro. O observado torna-se o observador. Tanto mais quanto maior for a distância.

Mas não só de marcadores geográficos se constituem as fronteiras identitárias aqui negociadas. Devido ao seu modelo de gestão, os circuitos têm guias próprios que, na maioria das vezes, conduzem as visitas no interior das fábricas. ${ }^{15} \mathrm{Se}$, por um lado, o objetivo é dar a conhecer como se fazem os objetos que nos rodeiam todos os dias, por outro, as visitas devem interferir o mínimo possível com uma produção que tem objetivos diários para cumprir. Desse modo, as máquinas não param, tal como os trabalhadores também não devem parar. Os visitantes querem ver os modos de fazer, mas o tempo de uma fábrica não se pode submeter ao tempo do lazer. Os trabalhadores e as máquinas estabelecem o primeiro e os guias e os visitantes tomam conta do segundo. Contudo, constituindo os lugares turísticos zonas privilegiadas de contacto, invariavelmente os dois tempos e os seus múltiplos atores cruzam-se, sendo no contacto entre visitantes e trabalhadores - muitas vezes em jeito inesperado de serendipity - que a dimensão relacional do turismo se revela.

Construídos a partir de cima, guiões e percursos de visita são definidos e orientados por administradores ou quadros superiores das empresas, em colaboração com os técnicos da autarquia responsáveis pelo projeto, em resposta a diretrizes especificas. ${ }^{16}$ Seguindo tendências estetizantes do capitalismo (e.g.,

15 As visitas também podem ser realizadas por guias internos das empresas (administradores ou trabalhadores que ocupam cargos intermédios), mas apenas excecionalmente. Por norma, são orientadas por guias que pertencem aos quadros ou prestam serviço no município de São João da Madeira, como foi o meu caso.

16 O guião de visita de cada fábrica é escrito a partir de uma primeira visita orientada por um administrador ou quadro superior da empresa, constituindo-se estes como as fontes principais. [continua] 
Lipovetsky e Serroy 2013), à transmissão do conhecimento associado aos processos produtivos, junta-se o objetivo de transformar o próprio espaço de produção em instrumento privilegiado de marketing da empresa, onde o lugar dos trabalhadores fica maioritariamente remetido aos modos de fazer, aos conhecimentos e habilidades individuais, em prol de um desígnio apresentado como coletivo que é o "sucesso da empresa".

Contudo, também pela pequena dimensão das fábricas visitáveis e as características dos processos de produção que permitem o desenho de percursos de visita lado a lado com os corredores de produção, a proximidade dos visitantes com os trabalhadores - num primeiro momento física e, num segundo, relacional - é inevitável, proporcionando aquilo que muitas vezes não se encontra no guião. Deste modo, ao trazer pequenos atos que podem ser associados a situações de proximidade e intimidade quotidianas, é, de certa forma, devolvido a estes corredores de produção industrial o seu caráter intrínseco de bastidores - para recorrer às definições de "região de bastidores" e de "fachada" de Goffman (2002 [1959]) - mesmo durante o ato de exibição turística que os quer temporariamente transformar em regiões de fachada. Tal é também verificável, do ponto de vista dos trabalhadores, na forma como estas interações turísticas se constituem, não só como um ato de exibição do seu trabalho, mas também como um ato expressivo de si mesmos, assumindo-se até como lugares para a contestação e a resistência quotidianas, em jeito de "arma dos fracos" (Scott 1985), numa tentativa de fuga às relações de poder e submissão tradicionais das relações de produção.

Corroborando a proposta de Bruner (1996), que vê os lugares turísticos como "zonas de fronteira", também estas visitas são lugares privilegiados para a análise dos processos de construção, contaminação e negociação de representações, de relações de poder e tensões sociais em espaços intersticiais e de fronteira. Tal como afirma Maria Cardeira da Silva (2004), os encontros turísticos contemporâneos são reveladores dos efeitos recíprocos nas negociações autoidentitárias dos seus participantes. Deste modo, ainda que podendo ser entendido enquanto work display - i.e., enquanto modo de exibição de processos e objetos industriais (MacCannell 1999 [1976]) - , este género de prática turística deverá ser visto como um modo de expressão do trabalho, que permite tanto ao trabalhador quanto ao visitante encontrar o seu lugar, semanticamente instável e disputável, no "drama universal do trabalho" (idem: 63).

[continuação] A este esboço é acrescentada informação proveniente de uma pesquisa de natureza predominantemente económica (i.e., volume de negócio, percentagem de exportação, principais clientes) e técnica (tecnologias, processos e produtos). Todos os guiões têm como base a narração do processo produtivo, à qual são acrescentadas temáticas específicas, consoante aquilo a que cada empresa pretende dar destaque (i.e., especificidades dos produtos, fatores de diferenciação da empresa no seu setor, práticas de proteção ambiental). As versões finais dos guiões têm de passar por um processo de validação por parte das empresas. 


\section{SENTIDOS DO TRABALHO: ENCONTROS E DESENCONTROS}

Apesar de São João da Madeira se localizar numa região marcada por vivências industriais, as empresas têm dificuldade em recrutar trabalhadores. E se é certo que, no período recente de crise económica, ${ }^{17}$ devido ao crescimento das taxas de desemprego, se assistiu a uma ligeira inversão da situação, ir trabalhar para uma fábrica ainda é das últimas opções. Na região, é recorrente ouvir-se a expressão: "vê lá, se não estudares vais parar a uma fábrica!" São os próprios trabalhadores fabris que, na sua maioria, afirmam que desejam para os seus filhos uma vida diferente da sua. Situam fora do mundo fabril todo um conjunto de expetativas para uma vida melhor. No entanto, porque muitos dos que têm níveis de escolaridade superiores não conseguem emprego na sua área de formação, hoje também já é comum ouvir: "sempre é melhor estar numa fábrica, que recebem um ordenado ao fim do mês, do que estar em casa sem fazer nada”. Ou seja, perante a falta de opção, trabalhar numa fábrica volta a ser uma possibilidade.

Em São João da Madeira, no caso da chapelaria, setor fundador do tecido industrial local, são essencialmente as condições ambientais das áreas de produção - calor, humidade e pelo no ar - que são pouco atrativas. No caso do setor do calçado, o segundo setor mais tradicional, organizado essencialmente em torno de pequenas fábricas, muitas delas de caráter familiar, a sua imagem esteve durante muitos anos associada à exploração de mão-de-obra domiciliária e infantil e às difíceis relações laborais entre pequenos patrões e trabalhadores. Apesar de as novas gerações de administradores quererem contrariar esta imagem, este é um dos setores com mais dificuldades no recrutamento de pessoal. O desabafo sobre a dificuldade em recrutar trabalhadores ouve-se também noutros setores, tanto mais em tempos em que se fala de uma nova revolução industrial - Indústria 4.0 - e se anunciam políticas públicas de investimento e desenvolvimento do setor secundário. Existem políticas de apoio e financiamento para o crescimento industrial. Talvez não haja é assim tanta gente que esteja disposta a trabalhar nas fábricas.

Dentro deste panorama, o trabalho de valorização e reconhecimento social da figura do trabalhador fabril é encarado como uma das principais missões do projeto em estudo. Quer com o propósito de mostrar aos mais jovens que a indústria pode ser vista como uma opção profissional, quer para contribuir para a melhoria da autoestima dos próprios trabalhadores das empresas que integram estes circuitos turísticos, propósito enunciado pelos próprios administradores das empresas:

"[O turismo industrial] Acaba por contribuir para dissipar o estigma que existe do sapateiro ou da indústria do calçado, permitindo que se veja a 
produção do calçado como uma arte. Com este projeto, temos recuperado um bocadinho a nossa autoestima, que se foi perdendo ao longo dos tempos" ["Entrevista a Manuel Fernandes, filho do fundador da empresa Evereste: 'Fazer sapatos é uma arte'”, Labor, 2 de junho de 2016]. ${ }^{18}$

A retórica de manutenção e captação de força de trabalho vai-se, assim, construindo a partir de cima, entre a elevação da figura do trabalhador à categoria de artesão, enquadrada por processos de estetização do trabalho, a valorização dos conhecimentos e competências associados à execução das tarefas produtivas e resolução de problemas, a exaltação das boas relações pessoais - que parecem querer substituir as relações de produção, muitas vezes expresso na frase "somos todos uma família" -, passando pela melhoria das condições de trabalho, comparadas com o passado ou até mesmo com as condições de trabalho das novas geografias de produção.

Contudo, se a maioria dos trabalhadores reconhece que gosta de mostrar aquilo que faz aos visitantes e que se sente valorizada com estas visitas turísticas, por vezes mais do que pelas próprias hierarquias internas - "porque temos alguém que tem interesse e quer saber como é o nosso trabalho" -, são muitas vezes também eles os primeiros a não incentivar os visitantes mais jovens a seguirem as suas pisadas.

Como captar o interesse de um jovem para um futuro no setor da indústria, se quando um grupo escolar entra numa fábrica e, em maior ou menor tom, a expressão que invariavelmente se escuta é: "estudem, estudem para não virem para aqui trabalhar!"? Ou quando uma criança fascinada, por exemplo, com o processo de fabrico dos lápis iguais aos que usa todos os dias, diz que gostava de trabalhar naquela fábrica quando crescesse e, em tom de conselho, ouve do outro lado a resposta para escolher um futuro melhor, "porque isto não interessa a ninguém!"?

Apesar da aposta na captação de público adulto e na internacionalização do projeto, com cada vez maior expressão, a maioria dos visitantes é oriunda de um contexto escolar. Nestes casos, a intenção dos professores de mostrar ambientes industriais enquanto futuros espaços de trabalho para os seus alunos encontra-se presente, agudizando-se quando estamos perante grupos escolares mais velhos. Porém, consoante a origem social dos alunos e a sua prestação académica, tal pode ser apresentado pelos próprios de formas distintas. Em tempos fulgurantes de uma retórica adepta do empreendedorismo, emergem dois cenários. Para grupos escolares com origem em classes sociais mais altas, o mundo industrial e os seus cargos superiores surgem como reservas de potencialidades para quem quiser seguir os desígnios do conhecimento, da inovação e da

18 A empresa Evereste é uma das fábricas de calçado que integra o turismo industrial de São João da Madeira. 
criatividade. Inversamente, em grupos com origens sociais mais desfavorecidas e prestações escolares mais baixas - muitas vezes presentes em turmas do ensino profissional - aquilo que os professores querem mostrar, em tom de quase vaticínio, é o que consideram ser o futuro dos seus alunos, "acabar numa produção":

"Eles bem querem ir para a área dos serviços, mas ainda têm de trabalhar muito para isso. Muitos deles talvez tenham de ir para trabalhos menos qualificados, como estes" [visitante português, professor, março de 2016].

Numa relação complexa entre escolaridade, ocupação profissional e reconhecimento social, a educação surge como uma via para vidas melhores, perante a evidência das desvantagens sociais e económicas das categorias mais baixas do trabalho fabril, atestadas agora pelo exterior através da experiência turística. "Isto é muito bom para eles terem noção de como as coisas são na realidade" é uma observação frequente dos professores que acompanham os grupos. $\mathrm{Na}$ saída das visitas às fábricas, alunos comentam entre si o incómodo dos cheiros intensos e das sonoridades ruidosas dos pavilhões fabris, ao mesmo tempo que debatem noções de justiça a partir, por exemplo, da história de trabalhadores que lhes contam que sempre ganharam o ordenado mínimo em toda a sua vida de trabalho. E à pergunta se gostara ou não da visita, um aluno respondeu-me de imediato: "estes trabalhadores deviam ser mais valorizados!".

Mas não é apenas junto dos mais jovens que a experiência assoberbada de estímulos sinestésicos que é entrar e percorrer os corredores de uma produção industrial desencadeia este tipo de reações. "Ai eu não gostava de trabalhar aqui! Nunca mais me queixo quando entrar numa sala de aula" foi a reação de uma professora à saída da fábrica de feltros para chapéus. "Estão 8 horas ali no mesmo sítio e a fazer a mesma coisa?", "E quanto ganham? Pouco, não?" - são questões recorrentes nas visitas. Por vezes, surgem mesmo observações mais contundentes:

“Devia haver máquinas para fazer o trabalho todo. É indigno estar aqui 8 horas por dia uma vida inteira! Dizem que as pessoas são burras. Mas experimentem estar aqui uma vida inteira. Elas não são burras! Eu talvez poderei ter de vir aqui parar, mas... [visitante portuguesa, desempregada, janeiro de 2017].

No entanto, apesar de o trabalho industrial parecer surgir no fim da cadeia de valor do trabalho como aquele que exige menores qualificações, com baixos salários e frágeis condições de trabalho, quando se trata de visitantes portugueses também não é raro ouvir a expressão, muitas vezes dirigida aos trabalhadores, acompanhada de um encolher de ombros, "o importante é que haja trabalho, não é?". Nestes momentos, em jeito de contraponto, assiste-se 
à exaltação daquilo que é visto como o espírito de abnegação destes trabalhadores, como contributo essencial para o crescimento da indústria nacional, apresentado quase em modo de desígnio coletivo. Como um visitante português emigrado em França comentou, numa conversa entre visitas, em que comparava as leis laborais francesas com as portuguesas:

"Pode ser bom para o país, mas não é bom para as pessoas. Mas para exportar é preciso pagar pouco..." [visitante português, reformado, junho de 2017].

Quando se trata de visitantes estrangeiros, essencialmente oriundos dos países da Europa Central, o impacto das condições de trabalho nas suas perceções é mais significativo, tal como é mais presente o interesse pelas lutas por direitos sociais e melhores condições de vida. Para alguns deles, estas visitas turísticas são também arenas para a negociação de representações sobre a economia portuguesa, agora num quadro de políticas económicas europeias:

"It's a good experience for central and northern European people to see and to know that there is hard work in Portugal and that things are not so easy as people expected. Some people come to the south of Europe thinking that it's la dolce vita and the press sometimes reports about the laziness in southern Europe. It's good to see that this is only a cliché [visitante alemão, professor responsável por um grupo de estudantes universitários que vieram a Portugal estudar os efeitos da crise económica no sul da Europa, abril de 2017].

\section{NOTAS FINAIS}

Ao nível dos discursos e práticas em torno do património industrial, é comum a crítica à promoção de uma memória seletiva e de uma nostalgia descontextualizada e despolitizada, particularmente no que diz respeito à história social da classe trabalhadora. No entanto, o que algumas pesquisas têm revelado é que, apesar disso, os visitantes utilizam crítica e ativamente esses antigos lugares industriais como ferramentas culturais e sociais de memória e de reflexividade (e.g., Smith 2006). O mesmo se verifica no caso em análise.

Ao configurar-se como recurso crescente de fenómenos de estetização do capitalismo, a integração de lugares industriais contemporâneos nos circuitos do turismo constitui-se, muitas vezes, pela incorporação de narrativas de exaltação de modelos económicos, assentes na retórica do empreendedorismo, da inovação e da criatividade. Nas visitas a fábricas em laboração em São João da Madeira, o recurso a este género de retórica é fortemente promovido pelos discursos oficiais, numa tentativa de combate a ideias que associam os espaços industriais a ambientes sujos, de exploração e de fomento de desigualdades 
sociais. No entanto, tal como o trabalho de campo nos consegue revelar, quando as práticas turísticas são entendidas como uma construção a múltiplas vozes convocadas na relação com o outro, discursos dissonantes e posicionamentos críticos vêm invariavelmente à tona. Tanto mais pelo modo particular como o turismo fornece uma audiência externa, com a qual se estabelecem trocas que formatam e produzem significados e valores (cit. Prista 2013: 378).

Umas das principais observações que emerge da pesquisa é que quer trabalhadores quer visitantes destas fábricas envolvem-se ativa e criticamente na criação de um sentido de visita, transformando-a, em parte, num ato de expressão de si mesmos. Memórias e experiências individuais são convocadas e interligadas pela performatividade da visita enquanto tentativas de contextualizar e entender a vida e o trabalho contemporâneos, mas também de negociar futuros. Assim, através da reflexividade do encontro turístico e da sua capacidade de mobilização de subjetividades, estas fábricas tornam-se não só em dispositivos de exibição, mas também em arenas de negociação de identidades sociais, experiências, expetativas de vida, tensões e resistências associadas ao mundo do trabalho e por ele convocadas.

\section{BIBLIOGRAFIA}

BENDIX, Regina, 2009, "Heritage between economy and politics: An assessment from the perspective of cultural anthropology", em Laurajane Smith e Natsuko Akagawa (orgs.), Intangible Heritage. Londres / Nova Iorque, Routledge, 253-269.

BRUNER, Edward M., 1996, “Tourism in the Balinese borderzone”, em Smadar Lavie e Ted Swedenburg (orgs.), Displacement, Diaspora and Geographies of Identity. Durham / Londres, Duke University Press.

CORBIN, Alain, 2001 [1995], História dos Tempos Livres. Lisboa, Teorema.

CORDEIRO, José Manuel Lopes, 2012, "Oportunidades e fragilidades do turismo industrial”, Revista Turismo \& Desenvolvimento, 1: 9-18.

CROUCH, David, Lars ARONSSON, e Lage WAHLSTROM, 2001, “Tourist encounters”, Tourist Studies, 1 (3): 253-270.

DAMIEN, Marie-Madeleine, e Claude SOBRY, 2001, Le tourisme industriel: Le tourisme du savoir-faire?. Paris, L'Harmattan.

ESTANQUe, Elísio, 1999, Classe e Comunidade Num Contexto em Mudança: Práticas e Subjectividades de Uma Classe em Recomposição. O Caso do Operariado do Calçado em S. João da Madeira. Coimbra, Faculdade de Economia da Universidade de Coimbra, dissertação de doutoramento.

GEERTZ, Clifford, 1977 [1973], The Interpretation of Cultures. Nova Iorque, Basic Books.

GIBSON, Chris, 2010, "Geographies of tourism: (un)ethical encounters", Progress in Human Geography, 34 (4): 521-527. 
GOFFMAN, Erving, 2002 [1959], A Representação do Eu na Vida Cotidiana, tradução de Maria Célia Santos Raposo. Petrópolis, Vozes.

GOUTHRO, Mary Beth, 2008, Consuming Heritage, Experiencing Identity: Finding Meaning Through Interpretations of Industrial Heritage Tourism. Brighton, The University of Brighton. GOUZÉVITCH, Irina, Marta C. LOURENÇO, e Ana Cardoso MATOS (orgs.), 2010, Expositions universelles, musées techniques et société industrielle. Lisboa, Edições Colibri / CIDEHUS - Universidade de Évora / Centre Maurice Halbwachs / CIUHCT.

GRABURN, Nelson, 1989 [1977], “Tourism: the sacred journey”, em V. Smith (org.), Hosts and Guests: The Anthropology of Tourism. Filadélfia, University of Pennsylvania Press, 21-36. HEWISON, Robert, 1987, The Heritage Industry: Britain in a Climate of Decline. Londres, Methuen.

HOSPERS, Gert-Jan, 2002, "Industrial heritage tourism and regional restructuring in the European Union", European Planning Studies, 10 (3): 397-404.

INE, 2011 , Censos 2011 . Lisboa, Instituto Nacional de Estatística.

LIPOVETSKY, Gilles, e Jean SERROY, 2013, L'esthétisation du monde: Vivre à l'age du capitalisme artiste. Paris, Gallimard.

LLURDÉS I COIT, Joan Carles, 2001, "Heritage tourism and textile 'model villages': the case of river park, Barcelona, Spain”, Tourism Recreation Research, 26 (1): 65-71.

LOFGREN, Orvar, 1989, “The nationalization of culture”, Journal of European Ethnology, XIX: $5-25$.

LOWEnTHAL, David, 2011 [1985], The Past is a Foreign Country. Cambridge, Cambridge University Press.

MACCANNELL, Dean, 1999 [1976], The Tourist: A New Theory of the Leisure Class. Berkeley e Los Angeles, University of California Press.

MARSH, Allison C., 2008, "Greetings from the factory floor: industrial tourism and the picture postcard”, Curator: The Museum Journal, 51 (4): 377-391.

NORA, Pierre, 1984-1992, Les lieux de mémoire. Paris, Gallimard.

PRISTA, Marta Lalanda, 2013, “Turismo e sentido de lugar em Óbidos: uma pousada como metáfora”, Etnográfica, 17 (2): 369-392.

SAMPAIO, Sofia, 2013, "Estudar o turismo hoje: para uma revisão crítica dos estudos de turismo", Etnográfica, 17 (1): 167-182.

SCOTT, James C., 1985, Weapons of the Weak: Everyday Forms of Peasant Resistance. New Haven / Londres, Yale University Press.

SILVA, Maria Cardeira da, 2004, "Introdução: por uma antropologia dos lugares turísticos", em Maria Cardeira da Silva (org.), Outros Trópicos. Novos Destinos Turísticos. Novos Terrenos da Antropologia. Lisboa, Livros Horizonte, 7-18.

SILVA, Mariana, 2015, A Cidade do Trabalho: Usos do Património Industrial (S. João da Madeira). Lisboa, Universidade Nova de Lisboa, trabalho de projeto do mestrado em Antropologia - Culturas Visuais.

SMITH, Laurajane, 2006, "Labour heritage: performing and remembering", em Laurajane Smith, Uses of Heritage. Londres e Nova Iorque, Routledge, 195-236.

XIE, Philip Feifan, 2015, Industrial Heritage Tourism. Bristol, UK, Channel View Publications. 